\title{
ORIGINAL
}

\section{Neurofilament light as an outcome predictor after cardiac arrest: a post hoc analysis of the COMACARE trial}

Lauri Wihersaari ${ }^{1}$, Nicholas J. Ashton 23,4,5, Matti Reinikainen', Pekka Jakkula ${ }^{6}$, Ville Pettilä ${ }^{6}$, Johanna Hästbacka ${ }^{6}$, Marjaana Tiainen ${ }^{7}$, Pekka Loisa ${ }^{8}$, Hans Friberg ${ }^{9}$, Tobias Cronberg ${ }^{10}$, Kaj Blennow ${ }^{2,11}$, Henrik Zetterberg 2,11,12,13, Markus B. Skrifvars ${ }^{14^{*}}$ and the COMACARE STUDY GROUP

(c) 2020 The Author(s)

\begin{abstract}
Purpose: Neurofilament light (NfL) is a biomarker reflecting neurodegeneration and acute neuronal injury, and an increase is found following hypoxic brain damage. We assessed the ability of plasma NfL to predict outcome in comatose patients after out-of-hospital cardiac arrest (OHCA). We also compared plasma NfL concentrations between patients treated with two different targets of arterial carbon dioxide tension $\left(\mathrm{PaCO}_{2}\right)$, arterial oxygen tension $\left(\mathrm{PaO}_{2}\right)$, and mean arterial pressure (MAP).

Methods: We measured NfL concentrations in plasma obtained at intensive care unit admission and at 24, 48, and $72 \mathrm{~h}$ after OHCA. We assessed neurological outcome at 6 months and defined a good outcome as Cerebral Performance Category (CPC) 1-2 and poor outcome as CPC 3-5.

Results: Six-month outcome was good in 73/112 (65\%) patients. Forty-eight hours after OHCA, the median NfL concentration was 19 (interquartile range [IQR] 11-31) pg/ml in patients with good outcome and 2343 (587-5829) $\mathrm{pg} / \mathrm{ml}$ in those with poor outcome, $p<0.001$. NfL predicted poor outcome with an area under the receiver operating characteristic curve (AUROC) of 0.98 (95\% confidence interval [CI] 0.97-1.00) at $24 \mathrm{~h}, 0.98(0.97-1.00)$ at $48 \mathrm{~h}$, and 0.98 $(0.95-1.00)$ at $72 \mathrm{~h}$. NfL concentrations were lower in the higher MAP $(80-100 \mathrm{mmHg})$ group than in the lower MAP $\left(65-75 \mathrm{mmHg}\right.$ ) group at $48 \mathrm{~h}$ (median, $23 \mathrm{vs} .43 \mathrm{pg} / \mathrm{ml}, p=0.04$ ). $\mathrm{PaCO}_{2}$ and $\mathrm{PaO}_{2}$ targets did not associate with NfL levels.
\end{abstract}

Conclusions: NfL demonstrated excellent prognostic accuracy after OHCA. Higher MAP was associated with lower NfL concentrations.

Keywords: Cardiac arrest, Prognostication, Biomarkers, Neurofilament light (NfL)

\footnotetext{
*Correspondence: markus.skrifvars@hus.fi

${ }^{14}$ Department of Emergency Care and Services, Helsinki University

Hospital and University of Helsinki, Helsinki, Finland

Full author information is available at the end of the article
}

\section{自




\section{Introduction}

Many patients resuscitated from out-of-hospital cardiac arrest (OHCA) suffer from hypoxic-ischaemic brain injury (HIBI) and die in the intensive care unit (ICU) without regaining consciousness $[1,2]$. Accurate prognostication is of paramount importance to prevent prolonged futile intensive care and, on the other hand, to avoid withdrawal of care in those who have a chance to recover [3, 4]. Current guidelines recommend a multimodal approach in the prognostication of cardiac arrest (CA) patients including clinical examination, radiological imaging, neurophysiological assessment, and biomarkers [5]. Unfortunately, some of these methods are not universally available $[6,7]$ and others can be affected by sedative medication and muscle paralysis often needed with targeted temperature management (TTM) [8].

Blood biomarkers are considered potential tools for prognostication because they are easy to obtain, and the results are not affected by the use of medication. Currently, neuron-specific enolase (NSE) is the most widely used biomarker in cardiac arrest (CA) patients [5]. NSE concentration at $48-72 \mathrm{~h}$ after $\mathrm{CA}$ has demonstrated moderate accuracy with areas under the receiver operating characteristic curves (AUROC) between 0.85 and 0.90 in predicting neurological outcome, but optimal cutoff values vary widely between studies [9-12]. Unfortunately, NSE is sensitive to blood sample haemolysis [13] and its prognostic ability is reduced in the elderly and in patients with shorter CA duration [14]. Therefore, novel biomarkers with superior performance to predict neurological outcome after OHCA are urgently needed to guide clinical management of this group of patients. Neurofilament light (NfL) is a $68 \mathrm{kD}$ cytoskeletal neuron-specific protein showing high promise as a clinically useful biomarker for acute brain conditions such as traumatic brain injury [15]. Recently, serum NfL was also shown to have excellent prognostic accuracy at 24-72 h from CA [16], but further external validation in independent patient cohorts is required before the routine use of NfL can be incorporated into clinical practice.

In the Carbon dioxide, Oxygen and Mean arterial pressure After Cardiac Arrest and REsuscitation (COMACARE) trial, we recently showed that targeting high-normal or low-normal carbon dioxide tension $\left(\mathrm{PaCO}_{2}\right)$, normoxia or moderate hyperoxia, and lownormal or high-normal mean arterial pressure (MAP) did not affect NSE concentrations in comatose OHCA patients $[17,18]$. Given the possible superior prognostic accuracy of NfL and its different sensitivity to axonal brain injury, we performed a post hoc sensitivity analysis and measured NfL concentrations in patients included in the COMACARE trial. We hypothesised first that compared to NSE, NfL would be an earlier and more accurate

\section{Take-home message}

Neurofilament light (NfL) appears to be a very accurate and early marker of long term neurological outcome after out-of-hospital cardiac arrest. Targeting a higher mean arterial blood pressure is associated with lower NfL levels than a standard blood pressure target.

biomarker of neurological outcome and that targeting high-normal $\mathrm{PaCO}_{2}$, moderate hyperoxia, and, second, high normal MAP would result in lower levels of NfL when compared with the lower targets.

\section{Methods}

\section{Study population and research approvals}

The COMACARE trial (NCT02698917) was a prospective, randomised pilot study of 120 comatose OHCA patients resuscitated from an initial shockable rhythm. The trial was a $2^{3}$ factorial trial exploring the effects of low-normal vs. high-normal arterial carbon dioxide tension (4.5-4.7 vs. $5.8-6.0 \mathrm{kPa}$ ), normoxia vs. moderate hyperoxia (arterial oxygen tension $10-15$ vs. $20-25 \mathrm{kPa}$ ) and low-normal vs. high-normal mean arterial pressure (65-75 vs. $80-100 \mathrm{mmHg}$ ) for $36 \mathrm{~h}$ post-resuscitation on markers of neurological damage, assessed primarily with neuron-specific enolase (NSE) concentrations in serum at $48 \mathrm{~h}$ after cardiac arrest. The study was conducted in seven ICUs in Finland and Denmark between March 2016 and November 2017. Randomisation was stratified according to TTM $\left(33{ }^{\circ} \mathrm{C}\right.$ or $36{ }^{\circ} \mathrm{C}$, according to sitespecific protocols). Neurological prognostication was performed according to European Resuscitation Council and European Society of Intensive Care Medicine guidelines [19]. The study protocol and the main results have been published previously $[17,18,20]$. In the current post hoc analysis, we measured the NfL concentrations in the blood samples of 112 Finnish patients included in the COMACARE trial. The original COMACARE study protocol was approved by the Ethics committee of Northern Savo Hospital District, Finland (decision no. 295/2015), and an amendment including the plan for the current analysis was approved in December 2017.

\section{Data collection}

We obtained blood samples at the time of ICU admission $(0 \mathrm{~h})$ and 24,48 , and $72 \mathrm{~h}$ after CA. The samples were centrifuged (2000 G, $10 \mathrm{~min}$ ) and stored at $-70{ }^{\circ} \mathrm{C}$ for later analysis. Plasma NfL concentration was measured using the commercially available Single Molecule Array (Simoa) NF-Light immunoassay (Quanterix, Billerica, MA, United States) in the Clinical Neurochemistry Laboratory of the University of Gothenburg (Mölndal, Sweden) in September 2019. Staff who conducted the 
analysis were blinded to all clinical data. The samples were diluted fourfold, and a single batch of reagents was utilised for all eight analytical runs needed to complete the analyses. For the low-concentration control sample (LCS; $6.9 \mathrm{ng} / \mathrm{l}$ ), the intra-assay coefficient of variation was $7.4 \%$ and the inter-assay coefficient of variation was $8.9 \%$, whilst for the high concentration quality control sample (HCS; $55.1 \mathrm{ng} / \mathrm{l}$ ), the corresponding coefficients of variation were $7.1 \%$ and $10.4 \%$, respectively.

Serum NSE concentration was measured using a COBAS e601 line (Hitachi High Technology Co, Tokyo, Japan) with an electrochemiluminescent immunoassay kit (Roche Diagnostics GmbH, Mannheim, Germany) by ISLAB laboratories (Kuopio, Finland) in January 2018. Because haemolysis can significantly affect NSE results, all samples were tested using the Roche haemolysis index, and the samples with a haemolysis level of more than $500 \mathrm{mg}$ of free haemoglobin per litre were excluded from the analyses [21].

Patient data regarding comorbidities, functional status, and resuscitation-associated factors were collected into an Internet-based database (Absolute Imaginary Software, Helsinki, Finland). A neurologist blinded to the results of the laboratory analysis, study group allocations, and treatment during hospital stay evaluated the neurological outcome using the Cerebral Performance Category $(\mathrm{CPC})$ scale at six months after CA via a telephone interview. We considered CPC $1-2$ as good outcome and CPC $3-5$ as poor outcome.

\section{Statistical analysis}

We present categorical variables as counts and percentages, including 95\% confidence intervals (CI) where applicable, and continuous variables as medians and interquartile ranges (IQR). We compared categorical variables with Pearson's Chi squared test or Fisher's exact test. We tested the normality of distribution of continuous variables with the Kolmogorov-Smirnov test and then compared normally distributed variables using the independent samples $t$ test, and non-normally distributed variables using the Mann-Whitney $U$ test or the Kruskal-Wallis test.

We assessed the ability of NfL and NSE to predict poor neurological outcome at 6 months by calculating the area under the receiver operating characteristic curve (AUROC). We compared the discriminative ability of NfL and NSE by comparing their AUROC values at ICU admission and at 24, 48 and $72 \mathrm{~h}$ after CA with a bootstrap method. The used bootstrap function is within the roc.test function (R program, https://www. rdocumentation.org). We assessed optimal cutoff values for NfL at 24-72 $\mathrm{h}$ after CA from the receiver operating characteristic curves (ROC). Because high specificity is important in prognostication, we assessed cutoff values with a specificity higher than $95 \%$. In addition, we determined cutoff values with the Youden method [22, 23]. We also determined the sensitivity, specificity, positive (PPV) and negative predictive values (NPV), and positive likelihood ratios $(\mathrm{LR}+)$ for these cutoff values. We also report cutoff values for the prediction of good functional outcome with high specificity and sensitivity.

To predict poor 6-month neurological outcome, we created a multivariable model, including patient age, receipt of bystander-given basic life support, and the time from collapse to the return of spontaneous circulation (ROSC). We then added NfL concentrations measured at 24,48 , and $72 \mathrm{~h}$ into this model and assessed the improvement of prognostic accuracy by comparing the AUROCs between the baseline model and the models after the addition of NfL. We also calculated the Net Reclassification Improvement (NRI) achieved with the addition of NfL into the baseline model. Event NRI (NRIe) is calculated as [(the number of patients with poor outcome for whom the predicted probability of poor outcome increases with addition of NfL to the baseline prediction model) - (the number of patients with poor outcome for whom the predicted probability decreases)]/[the number of all patients with poor outcome]. Similarly, non-event NRI (NRIne) is the net proportion of patients with good outcome given a lower probability of poor outcome after addition of NfL to the baseline prediction model. The overall NRI is the sum of NRIe and NRIne. The theoretical range of values for both NRIe and NRIne is -1 to +1 , and the range of values for overall NRI is -2 to $+2[24,25]$.

In addition, we determined the integrated discrimination improvement (IDI) that was obtained by adding NfL into the baseline prediction model. Event IDI (IDIe) is calculated for patients with poor outcome as [ (mean probability of poor outcome given by the model including NfL) - (mean probability of poor outcome given by the baseline model)] and non-event IDI (IDIne) for patients with good outcome as [(mean probability of poor outcome given by the baseline model) (mean probability of poor outcome given by the model including NfL)]. IDI is the sum of IDIe and IDIne. The theoretical range of values for both IDIe and IDIne is -1 to +1 , and the range of values for IDI is -2 to +2 $[25,26]$.

We conducted all statistical analyses with SPSS (SPSS, Chicago, IL, USA) version 25.0 and $\mathrm{R}$ version 3.5.1. We used two-tailed $p$ values with the level of significance set at a $p$ value less than 0.05 , and made no correction to the $p$ value despite the multiple testing. 


\section{Results}

Blood samples for NfL analysis were available for 112 of the 120 patients included in the COMACARE trial (Fig. 1). The baseline characteristics and resuscitationassociated factors are presented in Table 1. All patients were unconscious on arrival to the ICU and treated with TTM either in $33{ }^{\circ} \mathrm{C}$ or $36{ }^{\circ} \mathrm{C}$. The 6 -month neurological outcome was poor in 39 (35\%) patients, with 37 deaths (33\%) and two patients recovering to CPC 3. In 32 (86\%) of the deceased, the cause of death was HIBI. The investigations used to determine the prognosis in patients with a poor functional outcome are shown in the Electronic Supplementary Material (ESM) (Tables S1).

\section{Prognostic accuracy of NfL}

NfL concentrations were significantly higher in patients with poor outcome than in those with good outcome at all studied time points (Table 2, Fig. 2). The difference in $\mathrm{NfL}$ concentration between patients with poor and those with good outcome was at its greatest $48 \mathrm{~h}$ after cardiac arrest, when the median (IQR) NfL concentrations were $2343(587-5829) \mathrm{pg} / \mathrm{ml}$ and $19(11-31) \mathrm{pg} / \mathrm{ml}$, respectively $(p<0.001)$.

The ability of NfL to discriminate patients with poor outcome from those with good outcome was excellent at 24, 48, and $72 \mathrm{~h}$ after CA with AUROC values of 0.98 (95\% CI 0.97-1.00), 0.98 (95\% CI 0.97-1.00), and 0.98 (95\% CI 0.95-1.00), respectively (Fig. 3). The NfL concentration at ICU admission had a poor prognostic ability with an AUROC of 0.66 (95\% CI 0.54-0.77), which was clearly inferior compared to the AUROCs of NfL concentrations at 24, 48 and $72 \mathrm{~h}$ after CA $(p<0.001)$. NfL had an excellent ability to predict death from HIBI (ESM, Fig. S1). There was no difference in the prognostic accuracy of NfL depending on TTM target used during ICU care (ESM, Fig. S2).

\section{NfL compared with NSE and S100B}

Compared with NSE, NfL had a markedly better ability to discriminate patients with poor outcome from those with good outcome $(p<0.001$ for measurements at 24 and $48 \mathrm{~h} ; p=0.012$ at $72 \mathrm{~h}$ ) (Fig. 3). NfL was also better than S100B to discriminate between patients with good outcome and those with poor outcome at 24-72 $\mathrm{h}$ $(p<0.001)$ (Fig. 3). At ICU admission, the prognostic performance of NfL was poor, and the AUROCs were not significantly different between NfL and NSE $(p=0.185)$ and NfL and S100B ( $p=0.767)$ (Fig. 3).

\section{Cutoff values}

The cutoff values at 24,48 and $72 \mathrm{~h}$ after CA for obtaining a specificity of $99 \%$ in predicting poor outcome were 127,263 , and $344 \mathrm{pg} / \mathrm{ml}$, respectively. The corresponding sensitivities and positive and negative predictive values are presented in Table 2. Cutoff

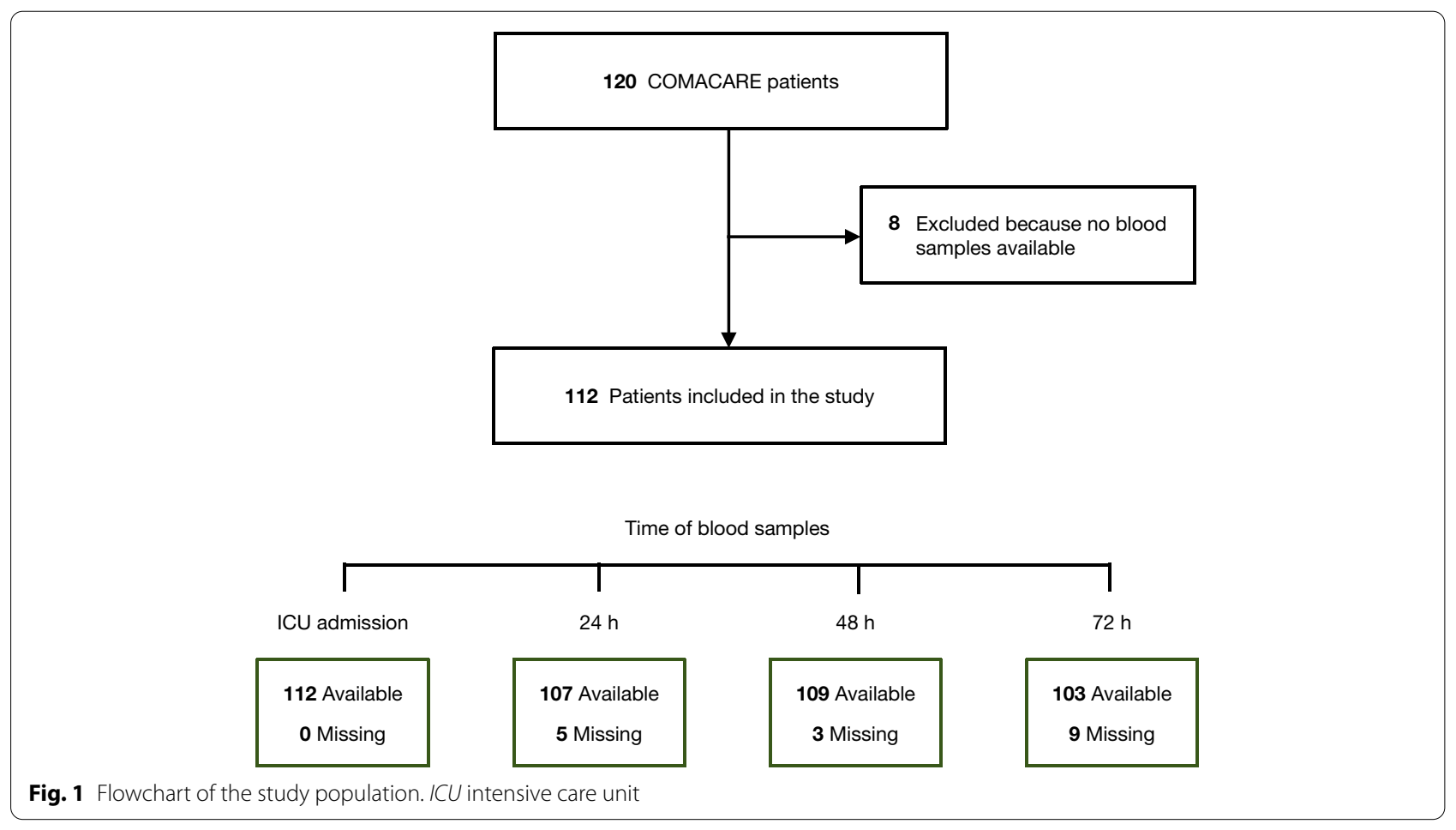


Table 1 Baseline characteristics of the study patients

\begin{tabular}{|c|c|c|c|c|}
\hline & All patients $(N=112)$ & CPC $1-2(N=73)$ & CPC 3-5 $(N=39)$ & $p$ value \\
\hline Age, median (IQR) (years) & $62(53-68)$ & $58(51-66)$ & $66(58-75)$ & 0.004 \\
\hline Male sex $[n(\%)]$ & $92(82.1)$ & $61(83.6)$ & $31(79.5)$ & 0.592 \\
\hline Weight [median (IQR), kg] & $85(72.3-93)$ & $85(72.5-94)$ & $83(70-90)$ & 0.646 \\
\hline \multicolumn{5}{|l|}{ Neurological function before cardiac arrest } \\
\hline Normal, CPC $1[n(\%)]$ & $103(92)$ & $67(91.8)$ & $36(92.3)$ & \multirow[t]{2}{*}{1} \\
\hline Some disability, CPC 2 [n (\%)] & $9(8)$ & $6(8.2)$ & $3(7.7)$ & \\
\hline \multicolumn{5}{|l|}{ Medical history } \\
\hline Hypertension [n (\%)] & $56(50)$ & $33(45.2)$ & $23(59)$ & 0.165 \\
\hline Chronic heart failure (NYHA 3 or 4) [n (\%)] & $9(8)$ & $4(5.5)$ & $5(12.8)$ & 0.151 \\
\hline Smoker $[n(\%)]^{b}$ & $35(31.3)$ & $22(30.1)$ & $13(33.3)$ & 0.235 \\
\hline \multicolumn{5}{|l|}{ Resuscitation factors } \\
\hline Bystander life support [n (\%)] & $93(83)$ & $66(90.4)$ & $27(69.2)$ & 0.004 \\
\hline Time to ROSC [median (IQR), min] & $21(16-26)$ & $17(15-22)$ & $25(22-32)$ & $<0.001$ \\
\hline \multicolumn{5}{|l|}{ Clinical status on ICU admission } \\
\hline GCS [median, (IQR)] $]^{c}$ & $3(3-3)$ & $3(3-5)$ & $3(3-3)$ & $<0.001$ \\
\hline APACHE II score, median (IQR) & $28(24-31)$ & $27(24-29)$ & $31(26-35)$ & $<0.001$ \\
\hline \multicolumn{5}{|l|}{ TTM } \\
\hline $33^{\circ} \mathrm{C}[n(\%)]$ & 75 (67) & $56(76.7)$ & 19 (48.7) & \multirow[t]{2}{*}{0.003} \\
\hline $36^{\circ} \mathrm{C}[n(\%)]$ & 37 (33) & $17(23.3)$ & $20(51.3)$ & \\
\hline
\end{tabular}

CPC Cerebral Performance Category, IQR interquartile range, NYHA New York Heart Association, ROSC return of spontaneous circulation, ICU intensive care unit, GCS Glasgow Coma Scale, SD standard deviation, APACHE // Acute Physiology and Chronic Health Evaluation

a Data missing for two patients

b Data missing for 13 patients

c Data missing for nine patients

Table 2 NfL concentrations (medians with IQRs) at ICU admission and 24, 48 and 72 h after cardiac arrest for patients with good outcome (CPC 1-2) and for those with poor outcome (CPC 3-5), and cutoff values with sensitivities, PPVs and NPVs at $24-72 \mathrm{~h}$ according to $99 \%$ of specificity

\begin{tabular}{|c|c|c|c|c|c|c|c|c|}
\hline \multicolumn{4}{|c|}{ NfL concentration pg/ml (IQR) } & \multicolumn{5}{|c|}{ Cutoff for $99 \%$ specificity } \\
\hline Time & CPC 1-2 & CPC 3-5 & $p$ value & $\mathrm{NfL} p g / m l$ & Sensitivity & PPV $(95 \% \mathrm{Cl})$ & NPV $(95 \% \mathrm{Cl})$ & $\begin{array}{l}p \\
\text { value }\end{array}$ \\
\hline ICU admission & $10.4(7.1-16)$ & $13.4(10.5-23.2)$ & 0.002 & & & & & \\
\hline $24 \mathrm{~h}$ & $12.1(8.3-23.7)$ & $761.9(217.6-1534.9)$ & $<0.001$ & 127 & $0.78(0.65-0.92)$ & $0.97(0.90-1.00)$ & $0.90(0.83-0.96)$ & $<0.001$ \\
\hline $48 \mathrm{~h}$ & $19.1(11-30.7)$ & $2342.6(586.9-5828.8)$ & $<0.001$ & 263 & $0.83(0.71-0.96)$ & $0.97(0.91-1.00)$ & $0.92(0.86-0.98)$ & $<0.001$ \\
\hline $72 \mathrm{~h}$ & $20.5(13.8-34.8)$ & $1727.9(643.1-4583.5)$ & $<0.001$ & 344 & $0.85(0.73-0.97)$ & $0.97(0.90-1.00)$ & $0.93(0.88-0.99)$ & $<0.001$ \\
\hline
\end{tabular}

CPC Cerebral Performance Category, NfL neurofilament light, IQR interquartile range, ICU intensive care unit, $P P V$ positive predictive value, NPV negative predictive value, $\mathrm{Cl}$ confidence interval

values determined according to the Youden method and according to specificities of $95-100 \%$, together with the corresponding sensitivities and positive and negative predictive values are presented in the ESM (Table S2). Cutoff values for identification of patients with good functional outcome are presented in the ESM (Table S3).

\section{$\mathrm{NfL}$ and clinical prognostication data}

The baseline multivariable model predicted a poor 6-month outcome with an AUROC of 0.86 (95\% CI 0.79-0.93) (Table S4). After NfL concentration at $24 \mathrm{~h}$ was added to this model, the AUROC improved to 0.98 (0.97-1.00), $p<0.001$. After adding NfL concentration at $48 \mathrm{~h}$, the AUROC increased to $0.99(0.98-1.00)$ $(p<0.001)$, and after adding NfL concentration at $72 \mathrm{~h}$, the AUROC was $0.99(0.98-1.00)(p<0.001)$. With the 


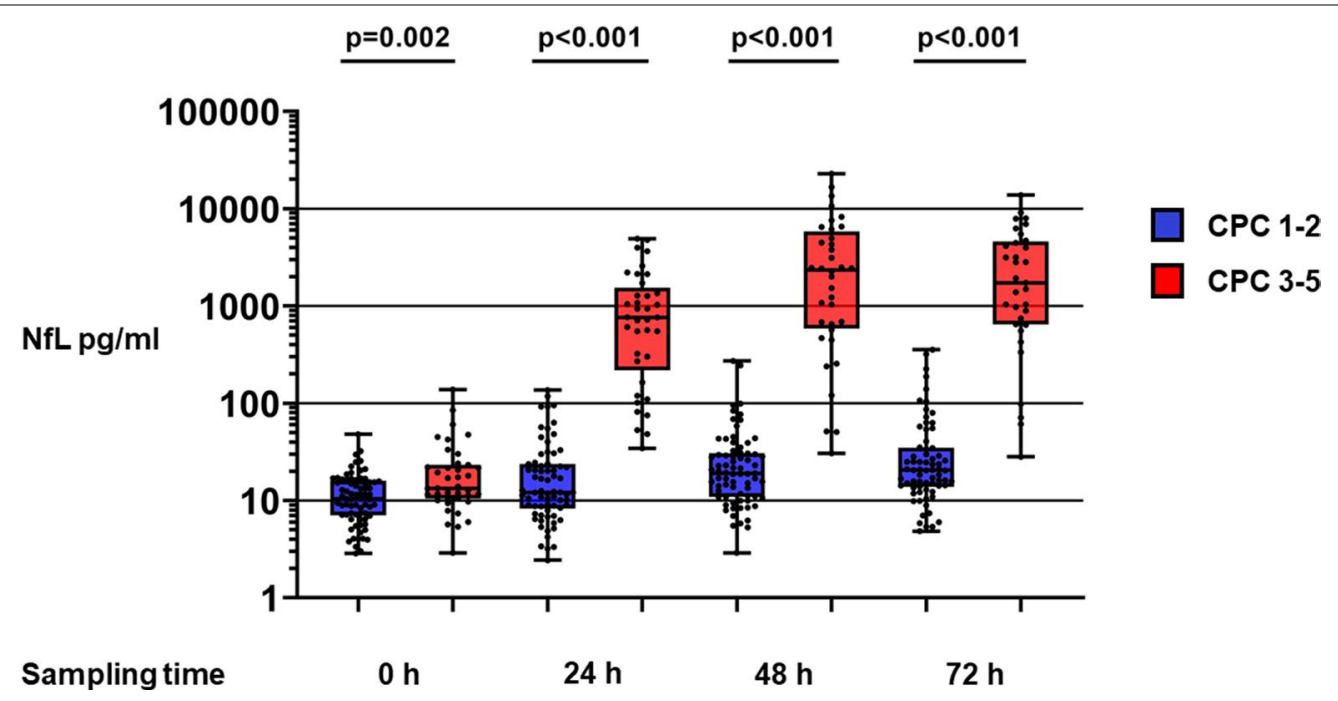

Fig. 2 Scatter plots and box plots presenting neurofilament light ( $\mathrm{NfL}$ ) concentrations at intensive care unit admission $(0 \mathrm{~h})$ and 24,48 and $72 \mathrm{~h}$ after cardiac arrest for patients with good outcome (Cerebral Performance Category [CPC] 1-2) and those with poor outcome (CPC 3-5) with a 10-based logarithmic scale. Dots present concentrations for individual patients. Each box depicts the interquartile range, the line inside the box shows the median value, and the whiskers show the range of values

inclusion of NfL to the baseline model at $24 \mathrm{~h}$, NRI was 1.51 (95\% CI 1.24-1.79); at $48 \mathrm{~h}$, NRI was 1.78 (95\% CI 1.58-1.97); and at $72 \mathrm{~h}$, NRI was 1.74 (1.53-1.94). The corresponding IDI values were 0.41 at $24 \mathrm{~h}, 0.45$ at $48 \mathrm{~h}$, and 0.45 at $72 \mathrm{~h}$ (ESM, Table S4).

\section{Haemolysis}

Detectable haemolysis (more than $100 \mathrm{mg}$ of free haemoglobin per litre) was observed in 157 (35\%) of all samples. Haemolysis did not increase NfL concentrations, whereas NSE concentrations were markedly higher in samples with haemolysis (ESM, Table S5, Figs. S3 and S4).

\section{$\mathrm{NfL}$ concentrations according to carbon dioxide, oxygen, and blood pressure targets}

There were no significant differences in NfL concentrations between the groups targeting low-normal or highnormal $\mathrm{PaCO}_{2}$ and normoxia or moderate hyperoxia at any of the studied time points (ESM Table S7). In patients assigned to the high-normal MAP group, NfL concentrations were lower than in patients in the low-normal MAP group at $48 \mathrm{~h}$ (median 23 [IQR 11-251] pg/ml vs. 43 [19$1066] \mathrm{pg} / \mathrm{ml},[p=0.04])$ and at $72 \mathrm{~h}(23[13-152] \mathrm{pg} / \mathrm{ml}$ vs 63 [21-1609] pg/ml [ $p=0.007])$ (ESM Table S6). NfL levels according to outcome in all intervention groups are presented in the ESM (Figs. S5-S7).

\section{Discussion}

Our findings provide evidence of the excellent ability of NfL to predict long-term neurological outcomes in a homogenous population of cardiac arrest patients resuscitated from a shockable rhythm and treated with TTM. Moreover, the results of this post hoc analysis offer additional information on the effects of carbon dioxide, oxygen, and blood pressure on the development of neurological injury after OHCA $[17,18]$. Using NfL as a marker of neurological injury, we found that a higher MAP target of $80-100 \mathrm{mmHg}$ was associated with lower NfL levels when compared with the conventional target of MAP $65-75 \mathrm{mmHg}$. We did not observe any significant difference in the NfL concentrations between the groups targeting low-normal and high-normal $\mathrm{PaCO}_{2}$, or normoxia and moderate hyperoxia.

The predictive accuracy of NfL observed in the current study is well in line with the findings of a previous study based on the TTM trial [16], whereas the cutoff values in our study were much lower. The patient populations in these two studies were different. The TTM trial included patients without any age limit and included patients with a non-shockable initial rhythm, whereas the COMACARE trial only included patients younger than 80 years, with a shockable initital rhythm and patients with time to ROSC less than $45 \mathrm{~min}$. Moreover, in the current study we have used a new commercially available kit for measuring NfL, while the Moseby-Knappe study used a custom-made assay $[27,28]$. 


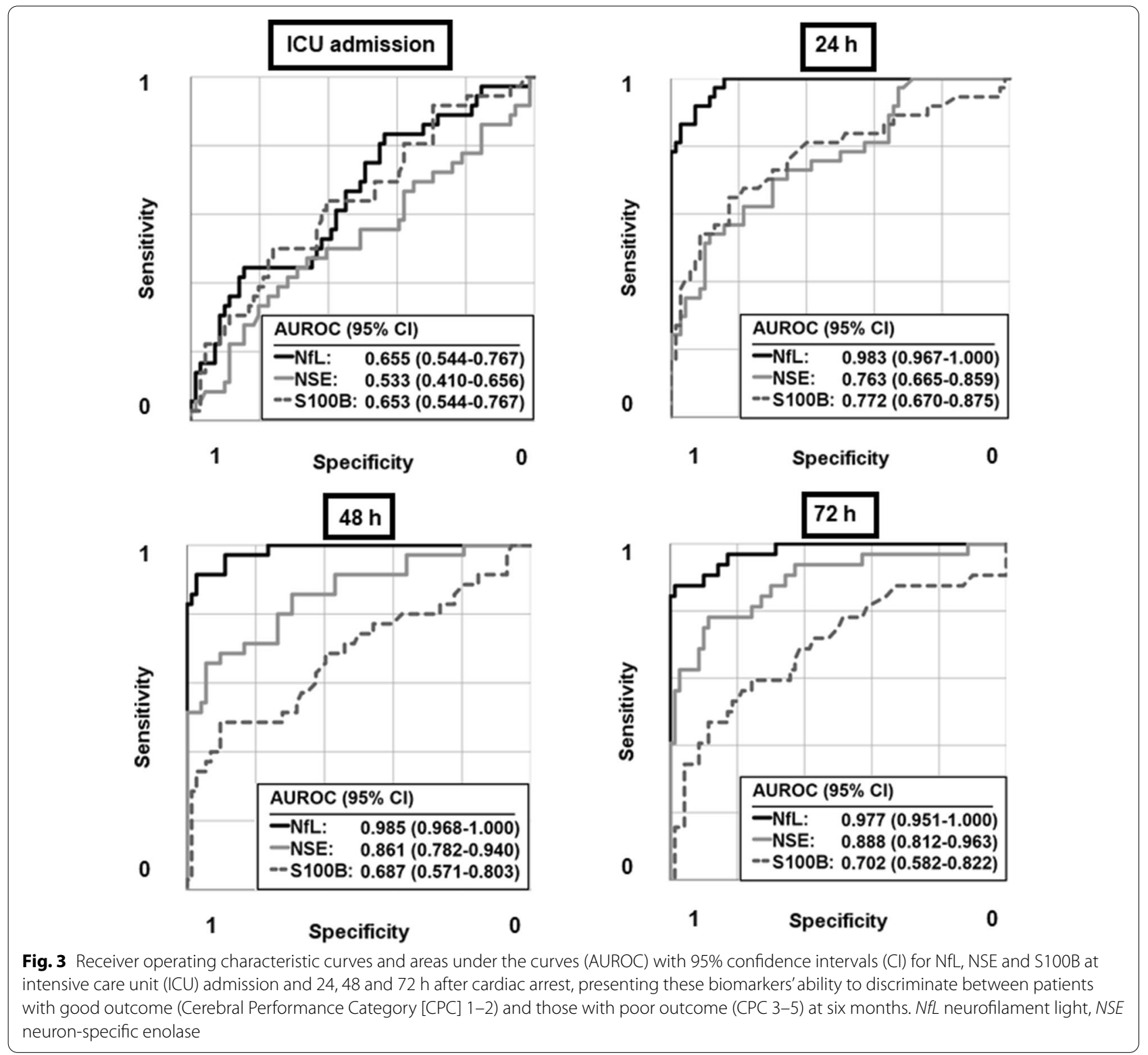

The AUROC values of NfL are very high at $24 \mathrm{~h}$ from CA. This level of accuracy has not been demonstrated for any other neurological biomarker [1], and our results reinforce the superiority of NfL compared to NSE [16]. One possible explanation for this can be the different distribution of these biomarkers in the grey and white matter of the brain. NSE is a neuronal enzyme that is more abundant in the grey matter [29]. NfL, in contrast, is a structural protein that can be found especially in large axons in the white matter [30]. Interestingly, radiological studies have suggested that white matter is particularly susceptible to ischaemic damage and that the extent of white matter injury seems to be associated with CA outcome [31]. In addition, it needs to be recognized that NSE, S100B and NfL have very different half-lives and this will influence the time trajectory of these biomarkers in brain injury patients [15]. The very long half-life of NfL may explain why it appeared, in contrast with NSE, to rise in the patients with good functional outcome as well.

Thus far, no biomarkers can reliably predict the outcome of OHCA patients at the time of hospital admission [1]. In the current study, we observed that the NfL levels at the time of admission were slightly higher in patients with poor outcome, but because of considerable overlap, this is not likely to be useful in clinical practice. At later time points, high NfL concentrations were predictive of 
poor outcome: no patients with concentrations higher than $390 \mathrm{pg} / \mathrm{ml}$ at any time point had a good outcome. However, our study population is too small to enable a threshold value to be proposed for prognostication.

One of the known limitations of NSE is that even mild haemolysis in the sample can result in erroneously elevated NSE levels [13]. Haemolysis is especially common in patients receiving continuous renal replacement therapy, intra-arterial balloon pump support, or extracorporeal membrane oxygenation, which are not uncommon interventions after OHCA. Importantly, the study by Moseby-Knappe et al. did not show any association between the level of haemolysis and NfL concentrations [16]. Our study also suggests that haemolysis does not influence NfL concentrations. Other conditions such as amyotrophic lateral sclerosis, HIV-associated dementia, and extensive traumatic brain injury (TBI) can affect NfL levels, but they are very uncommon in OHCA patients [16].

This additional analysis of the COMACARE trial shows an association between higher MAP and lower NfL concentrations, which may reflect the degree of brain injury. Given the small sample size and the post hoc design of the current study, this finding should be interpreted with caution and considered as hypothesis generating. Moreover, the absolute difference in NfL concentrations between the different MAP groups was small when compared with the 100-fold difference between the patients with good and poor outcomes. The possible beneficial effect of the higher MAP on clinical outcomes may be small compared to other factors, such as age, delay in resuscitation, and ROSC, and larger randomised trials are needed before the optimal blood pressure target after OHCA can be defined. Regarding carbon dioxide and oxygen, the results of the additional NfL analyses of the current study support the neutral results of the COMACARE trial on NSE.

\section{Strengths and limitations}

The current study has several strengths. First, the NfL results were not available to clinicians during patient care and could thus not have influenced treatment decisions. Second, the NfL concentrations were measured concurrently by the same laboratory. Third, we studied patients treated in multiple centres with TTM at both $33^{\circ} \mathrm{C}$ and $36{ }^{\circ} \mathrm{C}$.

A major limitation of the current study is the relatively small sample size. Moreover, our patient cohort was rather selected, including only patients with witnessed cardiac arrest with a shockable initial rhythm from a presumed cardiac origin and with time from collapse to ROSC between 15 and $45 \mathrm{~min}$. Future studies are needed to clarify the accuracy of NfL in unselected patient populations. The analysis was conducted in frozen samples, but the evidence suggests the stability of NfL in freeze-thaw samples [32]. Regarding the effect of carbon dioxide, oxygen, and MAP on NfL levels after OHCA, we acknowledge that the current study was designed post hoc, increasing the possibility of chance findings.

\section{Conclusions}

In unconscious OHCA patients treated with TTM, NfL had excellent prognostic accuracy already at $24 \mathrm{~h}$. Compared to NSE, NfL seems to be a more accurate biomarker for prognostication after $\mathrm{CA}$, and if validated in further samples, it has potential to replace NSE in the multimodal prognostication algorithms. Targeting a higher MAP of $80-100 \mathrm{mmHg}$ was associated with lower levels of NfL, generating a hypothesis that higher blood pressure after CA could attenuate brain injury.

\section{Electronic supplementary material}

The online version of this article (https://doi.org/10.1007/s00134-020-06218-9) contains supplementary material, which is available to authorized users.

\section{Author details \\ ${ }^{1}$ Department of Anaesthesiology and Intensive Care, Kuopio University Hospital, Kuopio, Finland. ${ }^{2}$ Department of Psychiatry and Neurochemistry, Institute of Neuroscience and Physiology, The Sahlgrenska Academy at the University of Gothenburg, Mölndal, Sweden. ${ }^{3}$ Wallenberg Centre for Molecular and Translational Medicine, University of Gothenburg, Gothenburg, Sweden. ${ }^{4}$ Institute of Psychiatry, Psychology and Neuroscience, King's College London, London, UK. ${ }^{5}$ NIHR Biomedical Research Centre for Mental Health and Bio- medical Research Unit for Dementia at South London and Maudsley NHS Foundation, London, UK. ${ }^{6}$ Department of Anaesthesiology, Intensive Care and Pain Medicine, University of Helsinki and Helsinki University Hospital, Hel- sinki, Finland. ${ }^{7}$ Department of Neurology, University of Helsinki and Helsinki University Hospital, Helsinki, Finland. ${ }^{8}$ Department of Intensive Care, Päijät- Häme Central Hospital, Lahti, Finland. ${ }^{9}$ Department of Clinical Sciences Lund, Anesthesiology and Intensive Care, Lund University, Skane University Hospital, Malmö, Sweden. ${ }^{10}$ Department of Clinical Sciences Lund, Neurology, Lund University, Skane University Hospital, Lund, Sweden. ${ }^{11}$ Clinical Neurochemistry Laboratory, Sahlgrenska University Hospital, Mölndal, Sweden. ${ }^{12}$ UK Dementia Research Institute at UCL, London, UK. ${ }^{13}$ Department of Neurodegenerative Disease, UCL Institute of Neurology, London, UK. ${ }^{14}$ Department of Emergency Care and Services, Helsinki University Hospital and University of Helsinki, Helsinki, Finland.}

\section{Acknowledgements}

The authors thank biostatistician Tuomas Selander, MSc, for help with the statistical analyses. COMACARE STUDY GROUP: Central Finland Central Hospital: Raili Laru-Sompa, Anni Pulkkinen, Mikko Reilama, Sinikka Tolmunen; Helsinki University Hospital: Minna Bäcklund, Jonna Heinonen, Johanna Hästbacka, Pekka Jakkula, Nina Lundbom, Marcus Norrgård, Marjatta Okkonen, Ville Pettilä, Markus B Skrifvars, Tarja Suhonen, Marjaana Tiainen, Tuukka Tikka, Marjut Timonen, Jussi Toppila, Miia Valkonen, Erika Wilkman; Jorvi Hospital: Teemu Hult, Tuomas Oksanen; Kuopio University Hospital: Stepani Bendel, Elina Halonen, Sari Rahikainen, Saija Rissanen, Eija Vaskelainen; North Karelia Central Hospital: Tanja Eiserbeck, Sirkku Heino, Helena Jyrkönen, Matti Reinikainen, Johanna Räsänen, Tero Surakka; Päijät-Häme Central Hospital:Talvikki Koskue, Petteri Kujala, Pekka Loisa, Marika Lähde; Tampere University Hospital: Jari Kalliomäki, Sari Karlsson, Atte Kukkurainen, Simo Varila.

\section{Funding}

Independent funding support has been received from Helsinki University; Helsinki University Hospital (State funding, Finland) (Grant no. TYH2018227); Stiftelsen Dorothea Olivia, Karl Walter och Jarl Walter Perkléns minne (Grant 
no. 2018, 2019); the Laerdal Foundation for Acute Medicine; Medicinska Understödsföreningen Liv och Hälsa (Grant no. 2018, 2019); Finska Läkaresällskapet; the Finnish Society of Anaesthesiologists; Orion Research Foundation, Sigrid Juselius Stiftelse and Svenska kulturfonden. The funding bodies had no input regarding the design, management, or reporting of the trial. Kaj Blennow is supported by the Swedish Research Council (\#2017-00915), the Alzheimer Drug Discovery Foundation (ADDF), USA (\#RDAPB-2018092016615), the Swedish Alzheimer Foundation (\#AF-742881), Hjärnfonden, Sweden (\#FO2017-0243), the Swedish state under the agreement between the Swedish government and the County Councils, the ALF-agreement (\#ALFGBG-715986), and European Union Joint Program for Neurodegenerative Disorders (JPND2019-466-236). Henrik Zetterberg is a Wallenberg Scholar supported by grants from the Swedish Research Council (\#2018-02532), the European Research Council (\#681712), Swedish State Support for Clinical Research (\#ALFGBG-720931), the Alzheimer Drug Discovery Foundation (ADDF), USA (\#201809-2016862), and the UK Dementia Research Institute at UCL. Open access funding provided by University of Helsinki including Helsinki University Central Hospital.

\section{Compliance with ethical standards}

\section{Conflicts of interest}

Markus Skrifvars reports speakers' fees and travel grants from BARD Medical (Ireland) and a research grant from GE Healthcare. Kaj Blennow has served as a consultant, at advisory boards, or at data monitoring committees for Abcam, Axon, Biogen, Julius Clinical, Lilly, MagQu, Novartis, Roche Diagnostics, and Siemens Healthineers, and is a co-founder of Brain Biomarker Solutions in Gothenburg AB (BBS), which is a part of the GU Ventures Incubator Program. Henrik Zetterberg has served at scientific advisory boards for Denali, Roche Diagnostics, Wave, Samumed and CogRx, has given lectures in symposia sponsored by Fujirebio, Alzecure and Biogen, and is a co-founder of Brain Biomarker Solutions in Gothenburg AB (BBS), which is a part of the GU Ventures Incubator Program.

\section{Protocol}

The protocol of the COMACARE study has been previously published [20].

\section{Open Access}

This article is licensed under a Creative Commons Attribution-NonCommercial 4.0 International License, which permits any non-commercial use, sharing, adaptation, distribution and reproduction in any medium or format, as long as you give appropriate credit to the original author(s) and the source, provide a link to the Creative Commons licence, and indicate if changes were made. The images or other third party material in this article are included in the article's Creative Commons licence, unless indicated otherwise in a credit line to the material. If material is not included in the article's Creative Commons licence and your intended use is not permitted by statutory regulation or exceeds the permitted use, you will need to obtain permission directly from the copyright holder. To view a copy of this licence, visit http://creativecommons.org/licen ses/by-nc/4.0/

\section{Publisher's Note}

Springer Nature remains neutral with regard to jurisdictional claims in published maps and institutional affliations.

Received: 12 May 2020 Accepted: 14 August 2020

Published online: 27 August 2020

\section{References}

1. Nolan JP, Berg RA, Callaway CW, Morrison L, Nadkarni V, Perkins GD, Sandroni C, Skrifvars MB, Soar J, Sunde K, Cariou A (2018) The present and future of cardiac arrest care: international experts reach out to caregivers and healthcare authorities. Intensive Care Med 44:823-832

2. Sandroni C, Combes A, Nolan JP (2019) Focus on post-resuscitation care. Intensive Care Med 45:1283-1287

3. Efendijev I, Folger D, Raj R, Reinikainen M, Pekkarinen PT, Litonius E, Skrifvars MB (2018) Outcomes and healthcare-associated costs 1 year after intensive care-treated cardiac arrest. Resuscitation 131:128-134
4. Sandroni C, Soar J, Friberg H (2016) Does this comatose survivor of cardiac arrest have a poor prognosis? Intensive Care Med 42:104-106

5. Nolan JP, Soar J, Cariou A, Cronberg T, Moulaert VR, Deakin CD, Bottiger BW, Friberg H, Sunde K, Sandroni C, European Resuscitation C, European Society of Intensive Care M (2015) European Resuscitation Council and European Society of Intensive Care Medicine 2015 guidelines for postresuscitation care. Intensive Care Med 41:2039-2056

6. Storm C, Nee J, Sunde K, Holzer M, Hubner P, Taccone FS, Friberg H, Lopez-de-Sa E, Cariou A, Schefold JC, Ristagno G, Noc M, Donker DW Andres J, Krawczyk P, Skrifvars MB, Penketh J, Krannich A, Fries M (2017) A survey on general and temperature management of post cardiac arrest patients in large teaching and university hospitals in 14 European countries-the SPAME trial results. Resuscitation 116:84-90

7. Nolan JP, Berg RA, Bernard S, Bobrow BJ, Callaway CW, Cronberg T, Koster RW, Kudenchuk PJ, Nichol G, Perkins GD, Rea TD, Sandroni C, Soar J, Sunde K, Cariou A (2017) Intensive care medicine research agenda on cardiac arrest. Intensive Care Med 43:1282-1293

8. Kirkegaard H, Taccone FS, Skrifvars M, Soreide E (2019) Postresuscitation care after out-of-hospital cardiac arrest: clinical update and focus on targeted temperature management. Anesthesiology 131:186-208

9. Steffen IG, Hasper D, Ploner CJ, Schefold JC, Dietz E, Martens F, Nee J, Krueger A, Jorres A, Storm C (2010) Mild therapeutic hypothermia alters neuron specific enolase as an outcome predictor after resuscitation: 97 prospective hypothermia patients compared to 133 historical non-hypothermia patients. Crit Care 14:R69

10. Storm C, Nee J, Jorres A, Leithner C, Hasper D, Ploner CJ (2012) Serial measurement of neuron specific enolase improves prognostication in cardiac arrest patients treated with hypothermia: a prospective study. Scand J Trauma Resusc Emerg Med 20:6

11. Streitberger KJ, Leithner C, Wattenberg M, Tonner PH, Hasslacher J, Joannidis M, Pellis T, Di Luca E, Fodisch M, Krannich A, Ploner CJ, Storm C (2017) Neuron-specific enolase predicts poor outcome after cardiac arrest and targeted temperature management: a multicenter study on 1053 patients. Crit Care Med 45:1145-1151

12. Stammet $P$, Collignon $O$, Hassager $C$, Wise MP, Hovdenes J, Aneman A, Horn J, Devaux Y, Erlinge D, Kjaergaard J, Gasche Y, Wanscher M, Cronberg T, Friberg H, Wetterslev J, Pellis T, Kuiper M, Gilson G, Nielsen N, Investigators TT-T (2015) Neuron-specific enolase as a predictor of death or poor neurological outcome after out-of-hospital cardiac arrest and targeted temperature management at $33^{\circ} \mathrm{C}$ and $36^{\circ} \mathrm{C}$. J Am Coll Cardiol 65:2104-2114

13. Nielsen N, Cariou A, Hassager C (2019) Physiological interventions in cardiac arrest: passing the pilot phase. Intensive Care Med 45:287-289

14. Wihersaari L, Tiainen M, Skrifvars MB, Bendel S, Kaukonen KM, Vaahersalo J, Romppanen J, Pettila V, Reinikainen M, FINNRESUSCl study group (2019) Usefulness of neuron specific enolase in prognostication after cardiac arrest: impact of age and time to ROSC. Resuscitation 139:214-221

15. Thelin EP, Zeiler FA, Ercole A, Mondello S, Buki A, Bellander BM, Helmy A, Menon DK, Nelson DW (2017) Serial sampling of serum protein biomarkers for monitoring human traumatic brain injury dynamics: a systematic review. Front Neurol 8:300

16. Moseby-Knappe M, Mattsson N, Nielsen N, Zetterberg H, Blennow K, Dankiewicz J, Dragancea I, Friberg H, Lilja G, Insel PS, Rylander C, Westhall E, Kjaergaard J, Wise MP, Hassager C, Kuiper MA, Stammet P, Wanscher MCJ, Wetterslev J, Erlinge D, Horn J, Pellis T, Cronberg T (2019) Serum neurofilament light chain for prognosis of outcome after cardiac arrest. JAMA Neurol 76:64-71

17. Jakkula P, Pettila V, Skrifvars MB, Hastbacka J, Loisa P, Tiainen M, Wilkman E, Toppila J, Koskue T, Bendel S, Birkelund T, Laru-Sompa R, Valkonen M, Reinikainen M, COMACARE Study Group (2018) Targeting low-normal or high-normal mean arterial pressure after cardiac arrest and resuscitation: a randomised pilot trial. Intensive Care Med 44:2091-2101

18. Jakkula P, Reinikainen M, Hastbacka J, Loisa P, Tiainen M, Pettila V, Toppila J, Lahde M, Backlund M, Okkonen M, Bendel S, Birkelund T, Pulkkinen A, Heinonen J, Tikka T, Skrifvars MB, COMACARE Study Group (2018) Targeting two different levels of both arterial carbon dioxide and arterial oxygen after cardiac arrest and resuscitation: a randomised pilot trial. Intensive Care Med 44:2112-2121

19. Sandroni C, Cariou A, Cavallaro F, Cronberg T, Friberg H, Hoedemaekers C, Horn J, Nolan JP, Rossetti AO, Soar J (2014) Prognostication in comatose survivors of cardiac arrest: an advisory statement from the European 
Resuscitation Council and the European Society of Intensive Care Medicine. Intensive Care Med 40:1816-1831

20. Jakkula P, Reinikainen M, Hastbacka J, Pettila V, Loisa P, Karlsson S, Laru-Sompa R, Bendel S, Oksanen T, Birkelund T, Tiainen M, Toppila J, Hakkarainen A, Skrifvars MB, COMACARE Study Group (2017) Targeting low- or high normal Carbon dioxide, Oxygen, and Mean arterial pressure After Cardiac Arrest and REsuscitation: study protocol for a randomized pilot trial. Trials 18:507

21. Wiberg $S$, Hassager $C$, Stammet $P$, Winther-Jensen $M$, Thomsen JH, Erlinge D, Wanscher M, Nielsen N, Pellis T, Aneman A, Friberg H, Hovdenes J, Horn J, Wetterslev J, Bro-Jeppesen J, Wise MP, Kuiper M, Cronberg T, Gasche Y, Devaux Y, Kjaergaard J (2017) Single versus serial measurements of neuron-specific enolase and prediction of poor neurological outcome in persistently unconscious patients after out-of-hospital cardiac arrest-a TTM-trial substudy. PLoS ONE 12:e0168894

22. Youden WJ (1950) Index for rating diagnostic tests. Cancer 3:32-35

23. Greiner M, Pfeiffer D, Smith RD (2000) Principles and practical application of the receiver-operating characteristic analysis for diagnostic tests. Prev Vet Med 45:23-41

24. Leening MJ, Vedder MM, Witteman JC, Pencina MJ, Steyerberg EW (2014) Net reclassification improvement: computation, interpretation, and controversies: a literature review and clinician's guide. Ann Intern Med 160:122-131

25. Pencina MJ, D'Agostino RB Sr, D’Agostino RB Jr, Vasan RS (2008) Evaluating the added predictive ability of a new marker: from area under the ROC curve to reclassification and beyond. Stat Med 27:157-172
26. Pickering JW, Endre ZH (2012) New metrics for assessing diagnostic potential of candidate biomarkers. Clin J Am Soc Nephrol 7:1355-1364

27. Hviid CVB, Knudsen CS, Parkner T (2020) Reference interval and preanalytical properties of serum neurofilament light chain in Scandinavian adults. Scand J Clin Lab Investig 80:291-295

28. Moseby-Knappe M, Pellis T, Dragancea I, Friberg H, Nielsen N, Horn J, Kuiper M, Roncarati A, Siemund R, Unden J, Cronberg T, Investigators TT-T (2017) Head computed tomography for prognostication of poor outcome in comatose patients after cardiac arrest and targeted temperature management. Resuscitation 119:89-94

29. Haque A, Polcyn R, Matzelle D, Banik NL (2018) New insights into the role of neuron-specific enolase in neuro-inflammation, neurodegeneration, and neuroprotection. Brain Sci 8(2):33. https://doi.org/10.3390/brainsci80 20033

30. Gaetani L, Blennow K, Calabresi P, Di Filippo M, Parnetti L, Zetterberg H (2019) Neurofilament light chain as a biomarker in neurological disorders. J Neurol Neurosurg Psychiatry 90:870-881

31. Luyt CE, Galanaud D, Perlbarg V, Vanhaudenhuyse A, Stevens RD, Gupta R, Besancenot H, Krainik A, Audibert G, Combes A, Chastre J, Benali H, Laureys S, Puybasset L, Neuro Imaging for Coma E, Recovery C (2012) Diffusion tensor imaging to predict long-term outcome after cardiac arrest: a bicentric pilot study. Anesthesiology 117:1311-1321

32. Keshavan A, Heslegrave A, Zetterberg H, Schott JM (2018) Stability of blood-based biomarkers of Alzheimer's disease over multiple freeze-thaw cycles. Alzheimers Dement (Amst) 10:448-451 